Classification

Physics Abstracts

$79.20 \mathrm{~K}-82.80$

\title{
EELS fingerprint of Al-coordination in silicates
}

\author{
P.L. Hansen $\left({ }^{1}\right)$, R. Brydson $\left({ }^{2}\right)$, D.W. $\operatorname{McComb}\left({ }^{3}\right)$ and I. Richardson $\left({ }^{4}\right)$
}

( $\left.{ }^{1}\right)$ Haldor Topsøe Research Laboratories, Nymøllevej 55, 2800 Lyngby, Denmark

(2) Dept. of Materials Science and Engineering, University of Guildford, Surrey GU2 5XH, UK

$\left(^{3}\right)$ Steacie Institute for Molecular Sciences, National Research Council, Ottawa, Ontario, K1A OR6, Canada

(4) Dept. of Materials Science, University of Oxford, Parks Road, Oxford OX1 3PH, UK

(Received October 29, 1993; accepted October 19, 1994)

Résumé. - Les seuils $\mathrm{Al}-L_{2,3}$ et $\mathrm{Al}-\mathrm{K}$ ont été enregistrés par spectroscopie des pertes d'énergie (EELS) pour les minéraux Béryl, Orthoclase, Sillimanite, Andalousite et Kyanite. Lorigine de certains pics visibles sur ces seuils a été attribuée à des transitions vers des orbitales moléculaires inoccupées dans les clusters $\mathrm{AlO}_{4}^{5-}$ et $\mathrm{AlO}_{6}^{9-}$, possédant respectivement la symétrie tétraèdrique et octaèdrique. Des différences ont été mises en évidence et la possibilité de les utiliser comme empreintes représentatives des diverses coordinations en oxygène autour des cations Al est discutée avec le soutien de calculs en diffusion multiple (MS).

\begin{abstract}
Al} L_{2,3}$ - and $\mathrm{Al} \mathrm{K-edges} \mathrm{from} \mathrm{the} \mathrm{minerals} \mathrm{Beryl,} \mathrm{Orthoclase,} \mathrm{Sillimanite,} \mathrm{Andalusite}$ and Kyanite have been measured using electron energy-loss spectroscopy (EELS). Peaks in the spectra have been assigned to transitions to empty molecular orbitals in the clusters $\mathrm{AlO}_{4}^{5-}$ and $\mathrm{AlO}_{6}^{9-}$ with tetrahedral and octahedral symmetry, respectively. Differences have been identified and the possibility of using these as a fingerprint for Al cation-coordination to oxygen is discussed in light of the results of multiple scattering (MS) calculations.
\end{abstract}

\section{Introduction.}

The ionization edges obtained in electron energy-loss experiments in a transmission electron microscope (TEM) show a fine-structure (ELNES), $0-25 \mathrm{eV}$ above the onset of the edges, which is related to the detailed unoccupied electronic structure of the material. For simple structures (e.g. diamond), band structure methods [1] have been used to calculate the site- and symmetryprojected density of unoccupied states and a satisfactory agreement with the ELNES structure has been reached. For materials with more complicated atomic structures, as found in many minerals, band structure methods are cumbersome and do not provide much help in interpreting experimental ELNES data. An alternative approach is based on a molecular orbital (MO) pic- 
ture combined with multiple scattering (MS) theory which was developed to model fine-structure in X-ray absorption spectra [2]. This approach has been used to model ELNES data from several mineral structures [3-8]. In these studies it has been shown that the ELNES obtained from different cations in many minerals is dominated by the local coordination geometry - i.e. the local arrangement of oxygen atoms around the cation, and it has been suggested that a fingerprint method could be developed to allow rapid identification of coordination symmetry and in some cases also phases. In earlier publications, we have discussed the interpretation of $\operatorname{Si} L_{2,3}$-edges in nesosilicates [6-8]. In the present work we use this framework to interpret ELNES of the $\mathrm{Al} L_{2,3^{-}}$ and $\mathrm{K}$-edges from a range of minerals containing aluminium in different nearest neighbour environments. We then apply our findings to the determination of the local aluminium coordination in Portland cement pastes.

\section{Experimental details.}

The minerals were provided by the Mineralogical Museum in Copenhagen, Denmark and the Oxford University Museum with the following reference numbers; Beryl - $\mathrm{Be}_{3} \mathrm{Al}_{2}\left(\mathrm{Si}_{6} \mathrm{O}_{18}\right)$ (1976.733), Orthoclase - $\mathrm{KAlSi}_{3} \mathrm{O}_{8}$ (OUM3538), Sillimanite - $\mathrm{Al}_{2} \mathrm{SiO}_{5}$ (1972.480), Andalusite - $\mathrm{Al}_{2} \mathrm{SiO}_{5}$ (1972.389) and Kyanite - $\mathrm{Al}_{2} \mathrm{SiO}_{5}$ (1970.316). In Beryl Al occupies an octahedral site while $\mathrm{Al}$ is tetrahedrally coordinated in Orthoclase. The minerals in the $\mathrm{Al}_{2} \mathrm{SiO}_{5}$-group all contain $\mathrm{Al}$ in octahedrally coordinated sites. There is a further tetrahedral $\mathrm{Al}$ site in Sillimanite and a 5-fold $\mathrm{Al}$ site in Andalusite.

For the preparation of TEM samples, the minerals were crushed and ground with mortar and pestle to a fine powder. The powder was suspended in ethanol and a drop of the suspension was placed on a holey carbon film supported on a copper grid and allowed to dry. Approximate chemical composition and crystal structure of the minerals were checked in a TEM using selected area electron diffraction and energy dispersive X-ray (EDX) analysis. EELS was carried out in a VG HB501 dedicated STEM using a parallel recording system [9]. The spectra were acquired in image mode using an effective collection angle of $8.3 \mathrm{mrad}$. This means we are within the regime of small momentum transfer and observed transitions should obey the dipole selection rules. The energy resolution was about $0.6 \mathrm{eV}$ at the $\mathrm{Al} L_{2,3}$-edge and $2-3 \mathrm{eV}$ at the $\mathrm{Al} \mathrm{K}$-edge. No attempt was made to investigate the effect of crystal orientation on the observed energy-loss spectrum.

We did not observe any effects in the spectra of possible radiation damage from the electron beam.

\section{Results and discussion.}

The $\mathrm{Al} L_{2,3}$ - and $\mathrm{K}$-edges of Beryl ( $\mathrm{Al}$ coord. no. C.N. $=6$ ) and Orthoclase (C.N. $\left.=4\right)$ are shown in figures $1 \mathrm{a}$ and $1 \mathrm{~b}$. The spectra are marked 6 and 4 respectively to indicate the coordination number of $\mathrm{Al}$ cations. A background of the form $A \cdot E^{-r}$ has been subtracted from each spectrum. As no attempt has been made to remove intensity due to plural (i.e. additional plasmon) scattering, this probably limits the accuracy of the background fit. In this present study we are only concerned with a qualitative comparison of the structure up to $10-20 \mathrm{eV}$ above the onset of the edges and the exact form of the background is therefore of little importance. However, we would like to stress that for reliable elemental quantification, especially of $\mathrm{Al} L_{2,3}$-edges, accurate deconvolution and background subtraction of edges is essential. The accuracy of the absolute energy scale of the spectrometer is limited to $1-2 \mathrm{eV}$ due to instabilities in the drift tube voltage. Therefore we have aligned the $L_{2,3}$-edges by assigning the Si $L_{2,3}$-edge (peak Si- $\beta$ ) to $108.3 \mathrm{eV}$, 
as measured by Batson et al. in $\mathrm{SiO}_{2}$ [10]. The absolute energy scale of the $\mathrm{K}$-spectra is the same as that of Waychunas and Brown [11] and Mc Keown et al. [12], who measured X-ray absorption spectra of several minerals with $\mathrm{Al}$ cations in tetrahedral and octahedral coordination with oxygen. Hence, the first peak (a) in the spectrum of Orthoclase was positioned at $1566 \mathrm{eV}$ and the first peak in the Beryl spectrum (seen as a shoulder on the low energy side of the main peak) was placed at $1568 \mathrm{eV}$.
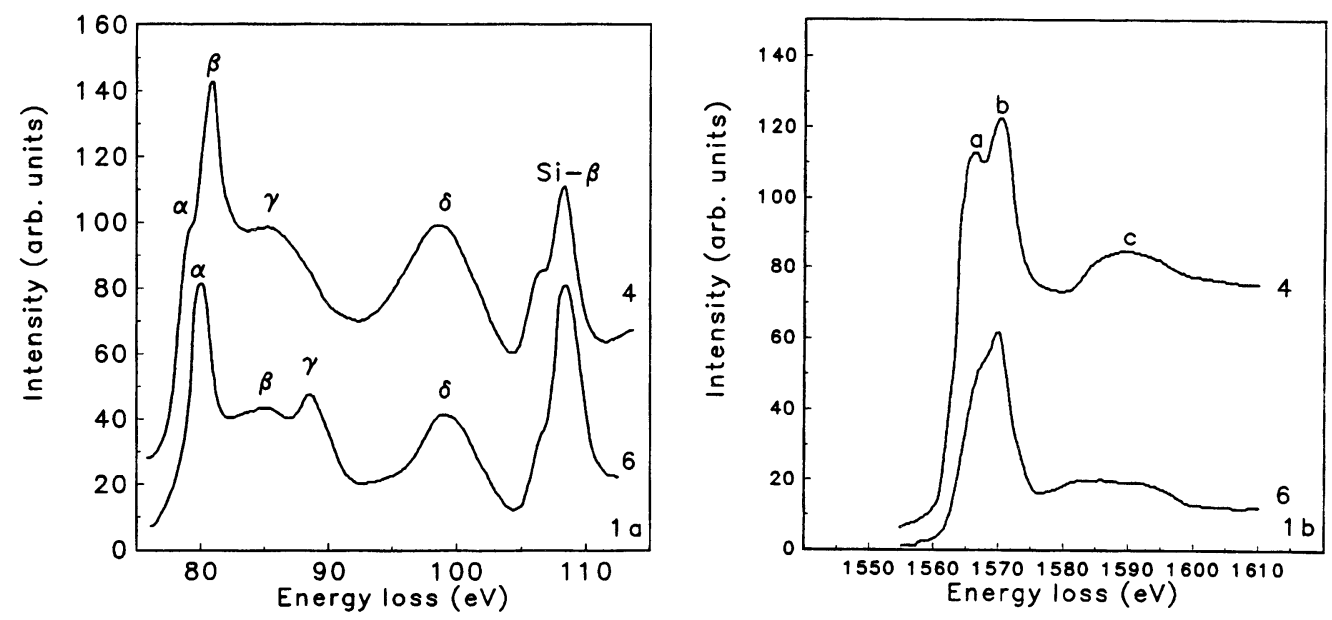

Fig. 1. - a) Shows $\mathrm{Al} L_{2,3}$-edge of Orthoclase (C.N. of $\left.\mathrm{Al}=4\right)$ and Beryl (C.N. of $\left.\mathrm{Al}=6\right)$. In b) the $\mathrm{K}$-edges of the same minerals are shown. The spectra represent fingerprints of tetrahedral and octahedral coordinated $\mathrm{Al}$ cations.

3.1 $\mathrm{Al} L_{2,3}$-ELNES. - The $\mathrm{Al} L_{2,3}$-ELNES reflects transitions from the $\mathrm{Al} 2 \mathrm{p}$ atomic level to unoccupied states coupled by the dipole selection rule. The $\mathrm{Al} L_{2,3}$-edge of Orthoclase is similar in shape to the Si $L_{2,3}$-edge of a large range of silicates [6, 7]. In the $\mathrm{Si} L_{2,3}$-edge the 4 peaks $\alpha, \beta, \gamma$ and $\delta$ were assigned to transitions from the $\mathrm{Si} 2 \mathrm{p}$ core states to the following molecular orbitals in a SiO $4-$ tetrahedron: $6 \mathrm{a}_{1}$ (s-like), $6 \mathrm{t}_{2}$ ( $\mathrm{p}$-like), $2 \mathrm{e}$ (d-like) and $7 \mathrm{t}_{2}$ (d-like), with some contribution from d-like MS resonance states from the first oxygen shell in the latter. Furthermore, there could be some contribution from double scattering in peak $\delta$. This interpretation was based on MO calculations of Tossel [13] and XAS work of Dehmer [14]. It is worth mentioning that the transition $2 \mathrm{p} \rightarrow 6 \mathrm{t}_{2}$ ( $\mathrm{p}$-like) is dipole allowed in tetrahedral symmetry, where there is no centre of inversion [7, 14]. The MO calculations of Tossel [13] showed that the structure of the empty $\mathrm{MOs}$ in $\mathrm{SiO}_{4}^{4-}$ and $\mathrm{AlO}_{4}^{5-}$ tetrahedra are almost identical the only difference being a small shift in energy for some of the MOs. We therefore propose the same assignment of the peaks $\alpha, \beta, \gamma$ and $\delta$ in the $\mathrm{Al} L_{2,3}$-edge of Orthoclase as is described above for the $\mathrm{Si} L_{2,3}$-edge.

The $\mathrm{Al} L_{2,3}$-edge of $\operatorname{Beryl}(\mathrm{C} . \mathrm{N} .=6)$ is similar to the $\mathrm{Si} L_{2,3}$-edge of Stishovite, a high-pressure form of $\mathrm{SiO}_{2}$ with $\mathrm{Si}$ cations in octahedral coordination with oxygen [15]. Based on MO calculations by Tossel [16] for $\mathrm{AlO}_{6}^{9-}, \mathrm{SiO}_{6}^{8-}$ and $\mathrm{MgO}_{6}^{10-}$ clusters of octahedral symmetry, the peaks $\alpha, \beta, \gamma$ and $\delta$ in the Beryl $\mathrm{Al} L_{2,3}$-edge may be assigned to orbitals of $7 \mathrm{a}_{1 \mathrm{~g}}$ (s-like), $7 \mathrm{t}_{1 \mathrm{u}}$ (p-like), $2 \mathrm{t}_{2 \mathrm{~g}}$ (d-like) and $3 \mathrm{e}_{\mathrm{g}}$ (d-like) symmetry. Transitions from the $\mathrm{Al} 2 \mathrm{p}$ core states to the orbital $7 \mathrm{t}_{1 \mathrm{u}}$ are not allowed by the dipole selection rules and the peak $\beta$ is seen to be reduced significantly in intensity when compared to the peak $\beta$ in the tetrahedral case. Vibronic excitations or distortions 
from perfect octahedral symmetry may be responsible for the non-zero intensity in peak $\beta$ in the octahedral case [15].

Similar spectra have been observed in other Al-containing materials which allows us to conclude that these spectra are representative fingerprints of the local $\mathrm{Al}$ coordination. Tetrahedrally coordinated $\mathrm{Al}$ cations in amorphous $\mathrm{Al}_{2} \mathrm{O}_{3}$ show an $L_{2,3} \mathrm{X}$-ray absorption spectrum similar to that in Orthoclase [15] while spectra similar to the octahedral case in figure 1a have been observed in Chrysoberyl [5], Rhodizite [3] and $\alpha-\mathrm{Al}_{2} \mathrm{O}_{3}$ [15]. Thus the main difference between the $\mathrm{Al} L_{2,3}$-ELNES of tetrahedrally and octahedrally coordinated aluminium appears to involve the intensity of the peak $\alpha$ which is derived from $\mathrm{Al}$ s-like states. In the tetrahedral case it appears as a weak low-energy shoulder on the main $\mathrm{Al}$ p-derived feature (peak $\beta$ ), whereas in the octahedral case peak $\alpha$ is a very strong intense feature and peak $\beta$ is very weak.

3.2 $\mathrm{Al} \mathrm{K}$-ELNES. - The $\mathrm{Al} \mathrm{K}$-ELNES reflects transitions from the $\mathrm{Al} 1 \mathrm{~s}$ atomic level to unoccupied states coupled by the dipole selection rule. The Al K-edge spectra of Orthoclase (C.N. $=4)$ and $\operatorname{Beryl}($ C.N. $=6)\left(\right.$ Fig. $1 \mathrm{~b}$ ) are simpler than the corresponding $\mathrm{Al} L_{2,3}$-edges. This arises since the excited electron is probing $\mathrm{p}$-like final states. In octahedral coordination, the $\mathrm{Al} \mathrm{p}$-like states transform as $\mathrm{t}_{1 \mathrm{u}}$ MOs and remain $\mathrm{p}$-like. In tetrahedral coordination, the lack of inversion symmetry causes substantial p-d mixing to occur as both the p-like and d-like states transform as $t_{2}$ MOs leading to a variety of possible final states.

Taftö [17] used the channeling effect to extract the tetrahedral and octahedral components from a K-edge spectrum of Sillimanite. The two components are similar to the spectra shown in figure $1 \mathrm{~b}$, even though the features are broader than in our case. Comparison with X-ray absorption spectra of the K-edges of Albite (C.N. = 4), Jadeite (C.N. = 4), Kyanite (C.N. = 6), Topaz (C.N. $=6)$, Nepheline (C.N. = 6) and Corundum (C.N. = 6) shows some differences between our ELNES data the XANES data of Waychunas and Brown [11] and Mc Keown et al. [12]. In general the XANES data are of higher resolution, showing more clearly resolved peaks. For tetrahedral $\mathrm{Al}$ the K-edge spectrum shows a single peak at $1566 \mathrm{eV}$. Our ELNES data from Orthoclase shows two peaks where peak (b) at $1570 \mathrm{eV}$ is stronger than peak (a) at $1566 \mathrm{eV}$.

In the octahedral case the XANES data show peaks at $1568 \mathrm{eV}$ and $1570-72 \mathrm{eV}$. The first peak being stronger than the second. Our ELNES data just resolves these two peaks, but the second peak is stronger than the first. The reason for this discrepancy may be due to a difference in site symmetry of $\mathrm{Al}$ ions in the structures analysed by McKeown et al. and the minerals studied by us.

The difference between the XANES and the ELNES data for tetrahedrally coordinated Al may be due to a difference in sensitivity of the two methods to the long range order in the material. The XANES data are collected mainly from glass-like material using the total yield of photo-electrons emitted from the sample. These electrons originate from a surface layer of about $10 \AA$ in thickness. EELS, however, probe all cations in crystals of $10-20 \mathrm{~nm}$ in thickness. Furthermore, multiple scattering calculations presented in the next section show that the single peak is split into two when the effect of more neighbouring shells are taken into account. We thus, tentatively, suggest that the double peak observed in the ELNES data is due to a long range order not probed by XANES.

The main difference, in the overall structure, between the Al K-edge ELNES of tetrahedrally and octahedrally coordinated aluminium involves the intensity of the first major feature relative to the high energy tail of the edge. The octahedral case exhibits a much stronger initial feature (relative to the high energy structure) compared with the tetrahedral case. This arises from the variety of possible final states ( $\mathrm{p}-\mathrm{d}$ mixing) accessible in tetrahedral coordination leading to a relatively broad range of features. 
3.3 Multiple SCATTERING CALCULATIONS. - Multiple scattering calculations using the ICXANES code of Vvedensky et al. [2] also support the view that the spectra shown in figures $1 \mathrm{a}$ and $1 \mathrm{~b}$ are representative of tetrahedral and octahedral units. In figure 2 we present results of MS calculations for single shell clusters of 4-, 5- and 6-coordinated Al cations. Phase shifts and atomic matrix elements were obtained by imposing a muffin tin potential on the structures of $\alpha-\mathrm{Al}_{2} \mathrm{O}_{3}$ and $\mathrm{AlPO}_{4}$ ( $\mathrm{Al}$ coordination octahedral and tetrahedral respectively). A damping term was included as to match experimental resolution. The effect of the core hole was simulated by the $(Z+1)^{*}$ approximation [4]. The absolute energy scales shown in the calculated spectra are arbitrary since they refer to the constant intersphere potential in the muffin tin approximation. However, the calculations do predict that the edge-onsets of both the $\mathrm{Al} L_{2,3}$-and $\mathrm{Al} \mathrm{K}$-edges are approximately $2-3 \mathrm{eV}$ lower in energy in tetrahedral coordination than in octahedral coordination to oxygen. This is in agreement with the experimental findings of Waychunas and Brown [11], Mc Keown et al. [12] and the calculations of Mc Keown [18] and arises due to the lower effective positive charge on aluminium in tetrahedral coordination as opposed to octahedral coordination.
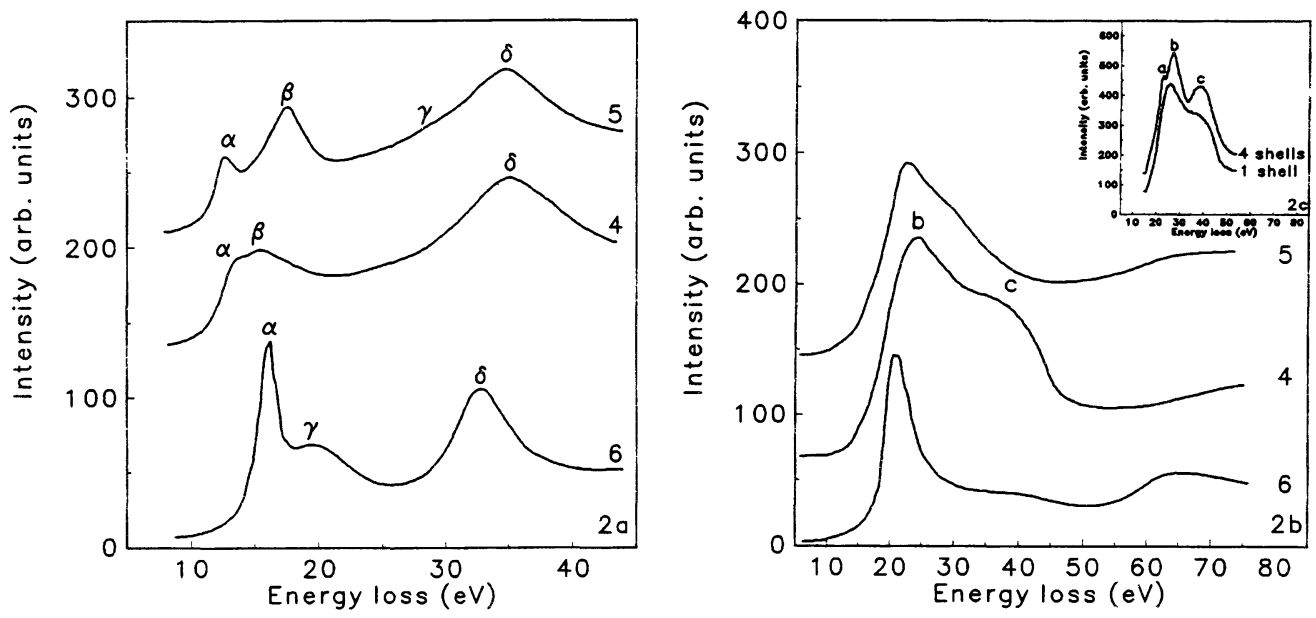

Fig. 2. - Multiple scattering (MS) calculations of a) $L_{2,3}$-edges and b) $\mathrm{K}$-edges of $\mathrm{Al}$ in tetrahedral (C.N. $=4)$, 5-fold (C.N. $=5)$ and octahedral $(\mathrm{C} . \mathrm{N} .=6)$ coordination to oxygen. In each case a single shelled cluster has been employed. c) MS calculation for Al K-edge in tetrahedral (C.N. = 4) coordination to oxygen showing the effect of increasing the number of shells used in the calculation.

Figure 2a shows the calculated $\mathrm{Al} L_{2,3}$-edges. The octahedral case $(\mathrm{C} . \mathrm{N} .=6)$ is the same as that in Engel et al. [3] and it successfully models the major features $\alpha, \gamma$ and $\delta$ of the observed $\mathrm{Al}$ $L_{2,3}$-ELNES of Beryl even though the simulated peak $\gamma$ is found at a somewhat lower energy than the corresponding peak in the experimental spectrum. Peak $\beta$ is not reproduced in the calculation since its origin is a dipole forbidden transition. The tetrahedral case $(C . N .=4)$ in figure $2 a$ shows peaks in the same positions $\alpha, \beta$ and $\delta$ as found in the experimental spectrum of Orthoclase. However, the intensity of peak $\beta$ is significantly reduced and peak $\gamma$ is not obviously reproduced in the calculation (although it is weakly apparent in the individual d-like component). This could be due to the use of a muffin tin form for the crystal potential which is employed to determine the various scattering phase shifts used in the MS calculations. MS calculations on larger clusters indicate that the form of the $\mathrm{Al} L_{2,3}$-ELNES is predominantly determined by the nearest neighbour 
environment. Hence, we find a qualitative agreement between the experimental and calculated spectra.

Figure $2 \mathrm{~b}$ shows the calculated $\mathrm{K}$-edges of $\mathrm{Al}$ cations in a single shell of 4-, 5- and 6-fold coordination to oxygen. The octahedral case shows a single strong peak followed by a much lower intensity feature some $20 \mathrm{eV}$ higher in energy. The tetrahedral case shows two peaks corresponding to the peaks (b) and (c) in the Al K-spectrum of Orthoclase. The separation of the peaks (b) and (c) in the calculated spectrum is about $13 \mathrm{eV}$, but it is nearer $20 \mathrm{eV}$ in the $\mathrm{Al} \mathrm{K}$-edge spectrum of Orthoclase. It is not clear what is the reason for this discrepancy. The relative intensities of these two features were found to be dependent on the precise phase shifts employed. This suggests that they will vary between different compounds containing tetrahedral $\mathrm{Al}$ sites. However, the MS calculations do predict the broad range of near-edge features experimentally observed for tetrahedrally coordinated Al. The initial feature in the single shell calculations, peak (b), is found to arise from predominantly intrashell scattering within the nearest neighbour coordination shell, and the increase in the relative intensity of this feature in octahedral coordination (relative to the tetrahedral case) is presumably due to the increased number of nearest neighbour ligands. Extensive MS calculations have shown that the splitting of the initial feature in the Al K-ELNES, most clearly seen as peak (a) in the Al K-ELNES of orthoclase (and also as a low energy shoulder in the Al K-ELNES of Beryl) arises from outerlying oxygen shells indicating that the details of the $\mathrm{Al}$-K-ELNES are also sensitive to the long range environment (next-nearest neighbour and beyond). This is illustrated in figure $2 \mathrm{c}$, for the case of tetrahedrally coordinated $\mathrm{Al}$, where MS calculations for 1 and 4-shelled clusters are compared. Note the appearance of peak (a). Thus, we find a qualitative agreement between experimental and calculated spectra.

3.4 EXTRACTION OF INDIVIDUAL SITE CONTRIBUTIONS FROM MIXED-COORDINATION COMPOUNDS. - To further test the idea of a fingerprint for the oxygen coordination of $\mathrm{Al}$ cations we have separated out the individual tetrahedral, octahedral and 5-fold components from the spectra of Sillimanite $(6,4)$, Andalusite $(6,5)$ and Kyanite $(6,6)$. As mentioned earlier Sillimanite and Andalusite have two different sites for the $\mathrm{Al}$ cations. One site is octahedral, while Sillimanite has a further 4-fold site and Andalusite has a 5-fold site. In Kyanite there are 4 slightly different 6-fold $\mathrm{Al}$ sites. The $\mathrm{Al} L_{2,3}$ - and $\mathrm{K}$-edges for the three minerals are shown in figures $3 \mathrm{a}$ and $\mathrm{b}$.
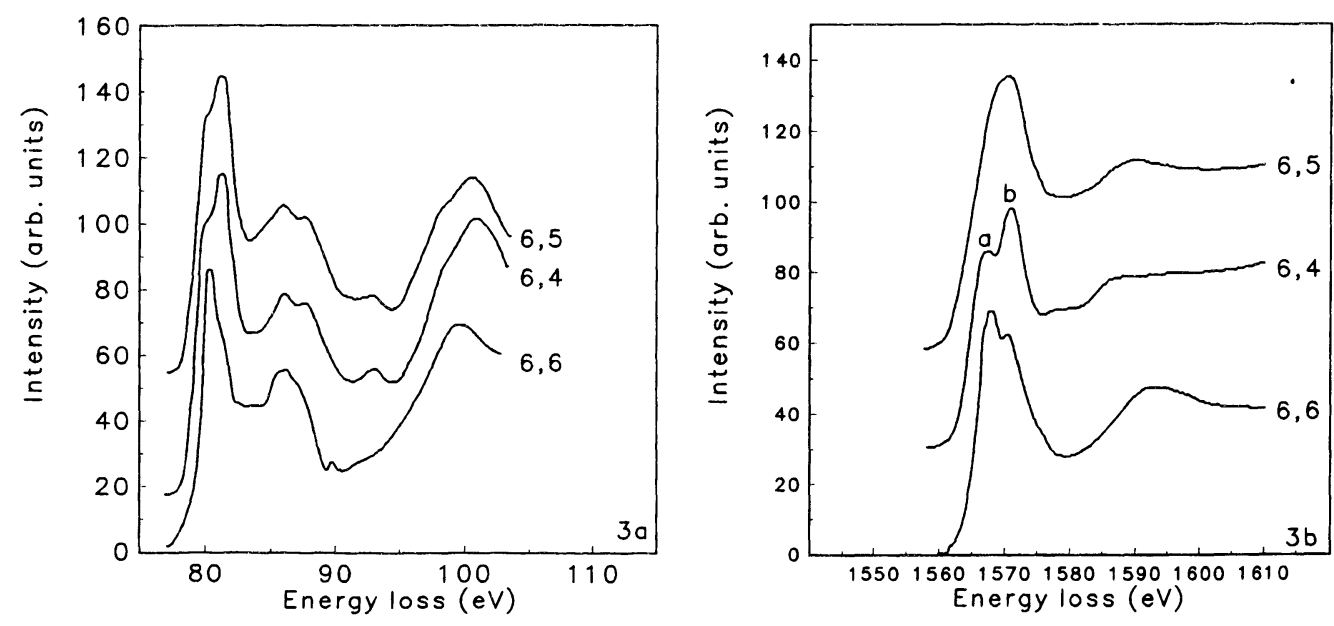

Fig. 3. - $\mathrm{Al} L_{2,3}$-edge a) and K-edges b) of the minerals Andalusite (C.N.: 6 and 5), Sillimanite (C.N.: 6 and 4) and Kyanite (C.N.: 6 and 6). 
Comparison of the $\mathrm{Al} L_{2,3^{-}}$and $\mathrm{Al} \mathrm{K}$-spectra of kyanite with those of beryl, indicate that there are some variations between the spectra for octahedrally coordinated $\mathrm{Al}$ obtained from different materials. This presumably arises since there are different octahedral $\mathrm{Al}$ sites in kyanite. However, the major features indicative of octahedrally coordinated $\mathrm{Al}$, that we have indicated above, are apparent - most notably the strong relative intensity of the feature at the edge-onset in both the $L_{2,3}$ and K-spectra. Since the spectra of kyanite represent an average over different octahedral sites and are therefore more representative of a standard octahedral fingerprint, we have employed these spectra in the extraction of the individual site contributions from the minerals containing mixed coordination. A subtraction of the spectrum of Kyanite (normalized over an energy window of $20 \mathrm{eV}$ from the edge onset and reduced in intensity by a factor 0.5) from the other two spectra should bring out the contributions from 4-fold (Sillimanite) and 5-fold (Andalusite) coordinated $\mathrm{Al}$ cations. The result of this manipulation is shown in figure 4.
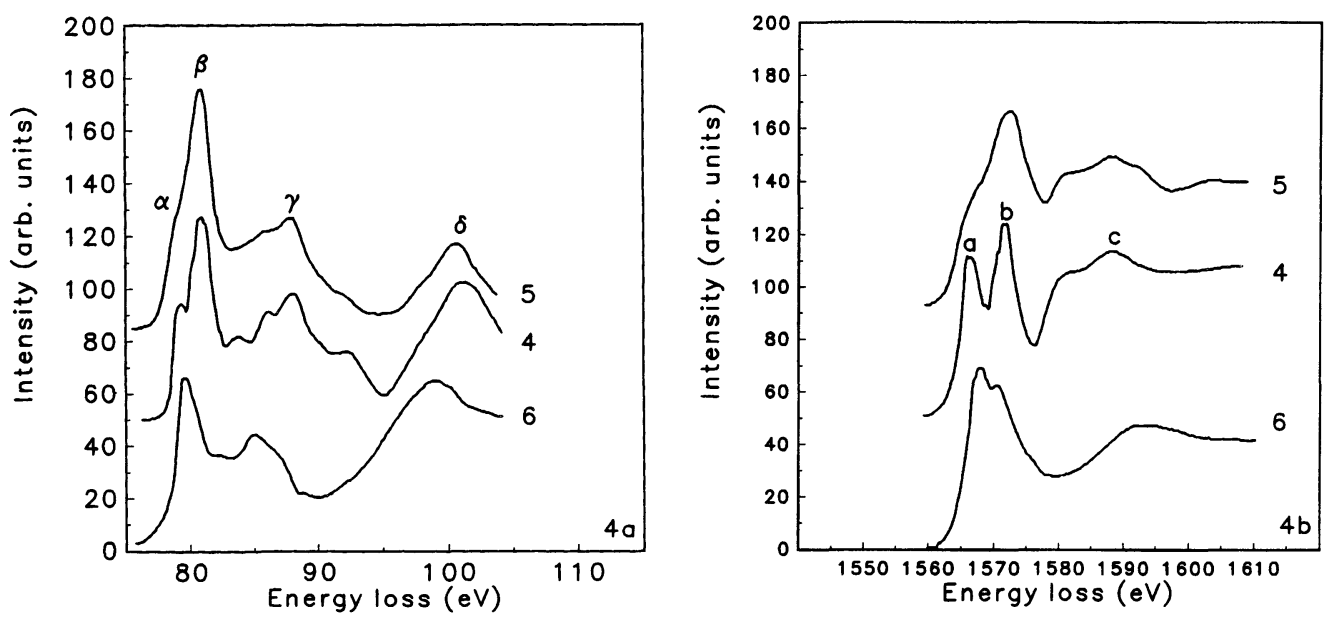

Fig. 4. - Manipulated spectra of Andalusite (C.N. = 5) and Sillimanite (C.N. = 4). The spectra of Kyanite $($ C.N. $=6)$ have been normalized and subtracted from the spectra of Andalusite and Sillimanite in order to reveal the components of the 5-fold and the 4-fold sites. a) shows the $\mathrm{Al} L_{2,3}$-edges. b) shows the $\mathrm{Al}$ K-edges.

For the $L_{2,3}$-edge in figure $4 \mathrm{a}$ we obtain spectra with 4 peaks $\alpha, \beta, \gamma$ and $\delta$ corresponding to the fingerprint spectrum of Orthoclase. The appearence of small extra peaks around $\gamma$ is due to different amounts of plural scattering in the different crystals selected for analysis and also to the choice of the interval used for normalisation. As expected from the original data and the MS calculations the spectra of $\mathrm{Al} L_{2,3}$-edges for 4- and 5-fold coordination are almost identical and are in qualitative agreement with the calculations for 4- and 5-fold coordination. At the Al K-edge, subtraction of the octahedral component from the spectrum of Sillimanite brings out the twopeak structure observed in Orthoclase even if it is somewhat exaggerated. The 5-fold case shows a strong peak at (b) with a shoulder at (a). This is the reverse of the calculation (Fig. 2b) where peak (a) is strong and peak (b) is a shoulder. The reason for this could be that a muffin tin potential is not a good enough approximation of the crystal potential in Andalusite or, alternatively, that the K-edge spectrum of Kyanite does not accurately represent the octahedral component of the spectrum of Andalusite. 


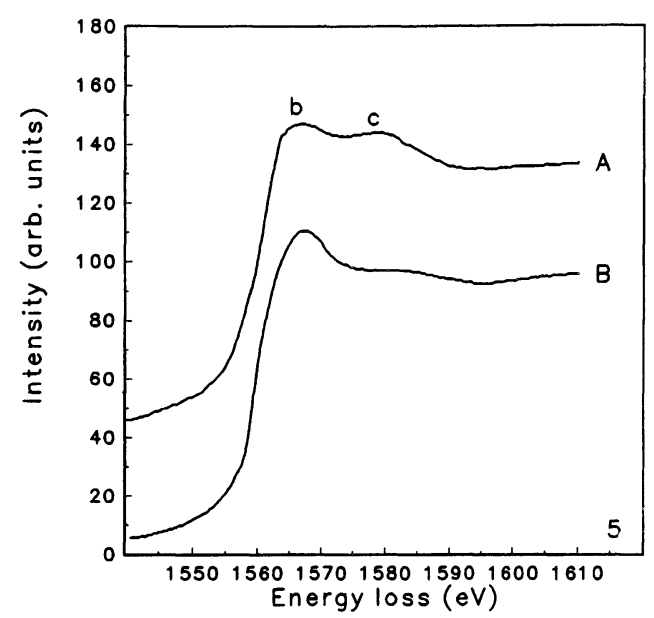

Fig. 5. - $\mathrm{Al} \mathrm{K-edge} \mathrm{spectra} \mathrm{at} \mathrm{low} \mathrm{resolution} \mathrm{(ca.} 3 \mathrm{eV}$ ) of the outer region (spectrum $\mathrm{A}$ ) and the inner region (spectrum $\mathrm{B}$ ) of a grain in a Calcium Silicate Hydrate.

\section{Application.}

A materials science application of this present work is provided by the determination of the local site symmetry of aluminium in calcium silicate hydrates (C-S-H) phases related to the principle binding phase in Portland Cement Pastes [19]. For our purposes we may envisage the hydrated cement sample as being divided into two regions: the inner and the outer product - so named since they refer to the location of the original unhydrated grains in the sample. The C-S-H outer product contains small amounts of aluminium and the $\mathrm{Al} \mathrm{K}$-edge spectrum obtained from this region is shown at low resolution (ca. $3 \mathrm{eV}$ ) in figure 5, curve $\mathrm{A}$, and at a corresponding higher resolution (ca. $1.3 \mathrm{eV}$ ) in figure 6. The spectra have not been deconvoluted. The statistics in the high resolution spectrum are poor due to both the extremely low concentration of $\mathrm{Al}(2-3$ atomic \%) and the beam sensitivity of the material which forced us to use a low dose technique to acquire the spectra. Despite this the spectrum more closely resembles that obtained from Orthoclase (Fig. 1b) and the MS calculation for tetrahedrally coordinated $\mathrm{Al}$ rather than the corresponding octahedral data, both in terms of the relative intensities of the initial peak compared with the higher energy features and in energy positions of peaks (b) and (c). Differing amounts of plural scattering will undoubtedly affect our results, however in all cases sample thicknesses were sufficiently similar for a qualitative comparison to be made. These results therefore suggest that $\mathrm{Al}$ occurs predominantly in tetrahedral sites in the outer product region, where it substitutes for silicon in the linear silicate chain structure as revealed by ${ }^{29} \mathrm{Si}$ magic angle spinning nuclear magnetic resonance (MASNMR) studies [19]. The splitting of peaks (a) and (b) in the Al K-ELNES (Fig. 6) is considerably less distinct and the intensity ratio reversed when compared with the spectrum of Orthoclase possibly indicating a reduction in long range order in the $\mathrm{C}-\mathrm{S}-\mathrm{H}$ phase.

Analysis of the inner product region, which also contains aluminium together with significant amounts of magnesium, reveals the low resolution $\mathrm{Al} \mathrm{K}$-edge spectrum shown in figure 5, spectrum B. Comparison with figure 5, spectrum A reveals that the Al K-edge of this region exhibits an increase in the intensity of the first peak (b) together with an increase in the splitting of features (b) and (c). Both these increases were found to be correlated with an increase in the relative concentrations of $\mathrm{Mg}$ and $\mathrm{Al}$. These observations may be explained by the existence of two phases 


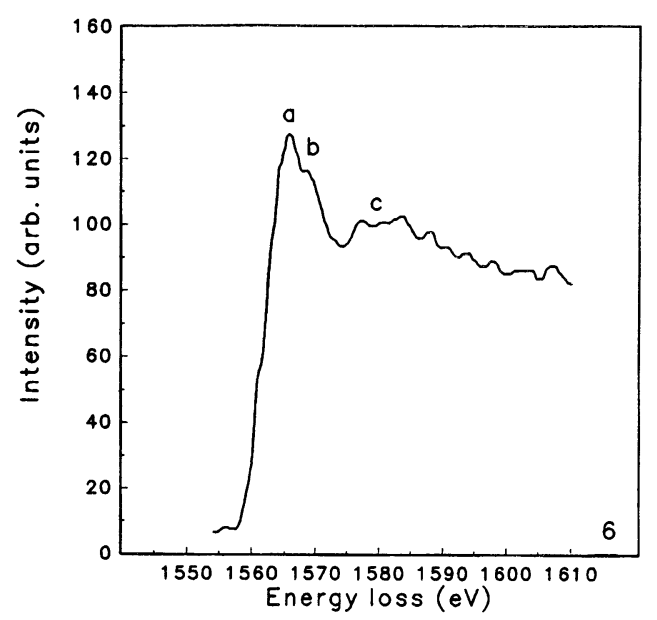

Fig. 6. - Al K-edge spectrum at high resolution (ca. $1.3 \mathrm{eV}$ ) of the outer region of a grain in a Calcium Silicate Hydrate.

in the inner product region. One contains $\mathrm{Al}$ in tetrahedral sites, as in the outer product, while the second magnesium-rich phase contains $\mathrm{Al}$ in octahedral sites where it has substituted for $\mathrm{Mg}$. These results back up both qualitatively and quantitatively the results of ${ }^{27} \mathrm{Al}$ MASNMR studies [19], however, the added benefits of high spatial resolution in determining local site symmetry by EELS can not be stressed too highly, especially in multiphase systems.

\section{Conclusions.}

It has been shown that the observed ELNES for aluminium cations in octahedral and tetrahedral coordination to oxygen exhibit significant differences. These arise from the different unoccupied molecular orbitals for each symmetry class into which core electrons may be excited. Similar changes in the silicon ELNES for octahedral and tetrahedral coordination have been observed previously, and it has been emphasised that small distortions of the coordination symmetry can cause large alterations in the observed ELNES. However, in the case of aluminium it appears to be valid to use the differences between the ELNES of octahedral and tetrahedral units as coordination fingerprints. This conclusion is supported by MS calculations which produce simulated spectra in qualitative agreement with the observed data. In general, the main features of the experimental spectra are predicted in the calculations but differences occur both in relative positions and relative intensities of the peaks. The choice of a muffin tin form for the crystal potential as well as small distortions from perfect tetrahedral and octahedral symmetry in the mineral structure are suggested to be the reasons for the discrepancies. The utility of the concept of a coordination fingerprint has been illustrated using the spectra of the $\mathrm{Al}_{2} \mathrm{SiO}_{5}$ polymorphs. The spectra from these minerals have been decomposed to show qualitatively the individual contributions of each symmetry species. It is emphasised that in attempting to distinguish between aluminium symmetry species both the $L_{2,3}$-edges and the $\mathrm{K}$-edges are of use. For example it is difficult to distinguish between andalusite and sillimanite using the $L_{2,3}$-edge, but the K-edge allows the minerals to be identified. Finally, it has been shown that the fingerprint interpretation can be applied to material science problems by a study of the inner and outer product regions of cement, in which the coordination of aluminium complexes was identified. 


\section{Acknowledgements.}

We thank Ole Johnsen from the Mineralogical Museum, Copenhagen for supplying the mineral samples. We would also like to thank the Royal Commission for the 1851 Exhibition (DWM) and the Royal Society (RB) for supporting this research, and the Danish Council for Technical Research for funding during a one year visit to the Cavendish Laboratory (PLH). We are grateful to Dr Phil Gaskell, Prof Mick Brown and Prof Archie Howie for many useful discussions about this work.

\section{References}

[1] Weng X., Rez P. and Sankey O.F., Phys. Rev. B40 (1989) 5694.

[2] Vvedensky D.D., Saldin D.K. and Pendry J.B., Computer Phys. Commun. 40 (1986) 421.

[3] Engel W., Sauer H., Zeitler E., Brydson R., Williams B.G. and Thomas J.M., J. Chem. Soc. Faraday Trans. I 84 (1988) 617.

[4] Brydson R., Sauer H., Engel W., Thomas J.M. and Zeitler E., J. Chem. Soc. Chem. Commun. (1989) 1010.

[5] Brydson R., EMSA Bulletin - Fall edition (1991).

[6] McComb D.W., Hansen P.L. and Brydson R., Microsc. Microan. Microstruct. 2 (1991) 561.

[7] Hansen P.L., Brydson R. and McComb D.W., Microsc. Microan. Microstruct. 3 (1992) 213.

[8] McComb D.W., Brydson R., Payne R.S. and Hansen P.L., J. Phys.: Cond. Matter 4 (1992) 1.

[9] McMullan D., Rodenburg J.M., Murooka Y. and McGibbon A.J., Inst. Phys. Conf. Ser. 98 (1989) 55.

[10] Batson P.E., Kavanagh K.L., Wong C.Y. and Woodall J.M., Ultramicroscopy 22 (1987) 89.

[11] Waychunas G.A. and Brown G.E., in 'EXAFS and Near-Edge structures III', K.O. Hodgson, B. Hedman and J.E. Penner-Hahn Eds., Springer Proceedings in Physics 2 (Springer Verlag: New York, 1984).

[12] Mc Keown D.A., Waychunas G.A. and Brown Jr. G.E., J. Non-Cryst. Solids 74 (1985) 349.

[13] Tossel J.A., J. Am. Chem. Soc. 97 (1975) 4840.

[14] Dehmer J.L., J. Chem. Phys. 56 (1972) 4496.

[15] Brytov I.A. and Romaschenko Y.N., Sov. Phys. Solid State 20 (1978) 664.

[16] Tossel J.A., J. Phys. Chem. Solids 36 (1975) 1273.

[17] Taftö J., Nucl. Instr. Methods Phys. Res. B2 (1984) 733.

[18] Mc Keown D.A., Phys. Chem Minerals 16 (1989) 678.

[19] Richardson I.G., Groves G.W., Brydson R. and McComb (D.W.), J. Am. Cer. Soc. 76 (1993) 2285; Brydson R., Richardson I.G., McComb D.W. and Groves G.W., Solid State Comm. 88 (1993) 183. 